\title{
AVALIAÇÃO DA FERTILIDADE DOS SOLOS DAS VÁRZEAS DO MUNICÍPIO DE SOUSA, PB
}

\author{
Lúcia Helena Garófalo Chaves ${ }^{1}$, Ivonete Berto Menino², Ivaldo Antonio de Araújo \\ e Iêde de Brito Chaves ${ }^{3}$
}

\begin{abstract}
RESUMO
Em face da importância dos Vertissolos, dos solos Aluviais eutróficos e dos Podzólicos VermelhoAmarelo eutrófico, das áreas circunvizinhas do canal Coremas/Sousa, Estado da Paraíba, Brasil, nas atividades agrícolas a serem desenvolvidas nesta região com o uso da irrigação, este trabalho teve como objetivo avaliar a fertilidade desses solos. Foram analisadas, quimicamente, amostras de terra dos horizontes superficiais e subsuperficiais de sessenta e seis perfis. Em geral, essas amostras de terra apresentaram valores de $\mathrm{pH}$ variando entre moderadamente ácido e alcalino, altos teores de $\mathrm{Ca}^{++} \mathrm{Mg}^{++}$, teores de $\mathrm{K}^{+}$e $\mathrm{P}$ variando entre baixo e alto, CTC variando de moderada a muito alta e baixos teores de matéria orgânica. $\mathrm{O}$ estudo mostrou que ocorrem problemas de salinidade (CEes $>4$ $\mathrm{dS} . \mathrm{m}^{-1}$ ) e sodicidade (PST> 8\%) em, aproximadamente, $19 \%$ e $52 \%$ da área estudada, respectivamente.
\end{abstract}

Palavras-chave: solos de várzea, fertilidade, salinidade

\section{EVALUATION OF FERTILITY OF LOWLAND SOILS FROM SOUSA-PB MUNICIPALITY}

\begin{abstract}
Due to importance of the Vertisols, eutrophic Alluvial soil and eutrophic Red Yellow Podzolic soil from the neighbouring areas around Coremas/Sousa canal, State of Paraíba, Brazil, in view of the agricultural activities to be developed in these regions with the use of irrigation, the objective of this study was to assess fertility level of these soils. Soil samples of surface and subsurface horizon of 66 soil profiles were analysed for chemical properties. In general, soil samples presented moderate acid to alkaline $\mathrm{pH}$ values, high values of $\mathrm{Ca}^{++} \mathrm{Mg}^{++}$, values of $\mathrm{K}^{+}$and $\mathrm{P}$ ranged from low to high, values of CEC ranged from moderate to high and low values of organic matter. The study revealed salinity $\left(\right.$ ECse $\left.>4 \mathrm{dS} . \mathrm{m}^{-1}\right)$ and sodicity (ESP $\left.>8 \%\right)$ problems in approximately $19 \%$ and $52 \%$ of the area studied, respectively.
\end{abstract}

Key words: lowland soils, fertility, salinity

\section{INTRODUÇÃO}

A irregularidade da distribuição temporal e espacial das chuvas nas regiões semi-áridas torna a atividade agrícola um empreendimento de alto risco. $\mathrm{O}$ armazenamento da água em grandes barragens e o fornecimento às plantas, com o uso da irrigação, têm sido o grande objetivo dos atuais governos, visando à instalação de pólos agro-industriais e a oferta de frutas "in natura" para exportação.

Considerando que a produção agrícola não depende apenas

\footnotetext{
${ }^{1}$ Professora Titular do Departamento de Engenharia Agrícola do Centro de Ciências e Tecnologia da UFPB, CP 10087, CEP 58109-970 Campina Grande, PB

${ }^{2}$ Engenheiros Agrônomos, MSc., Pesquisador da Empresa Estadual de Pesquisa Agropecuária-PB/SAIA, CP 275, CEP 58013-290 João Pessoa, PB

${ }^{3}$ Professor Adjunto do Departamento de Solos e Engenharia Rural do Centro de Ciências Agrárias da UFPB, CP 66, CEP 58397-000 Areia, PB
} 
do fornecimento de água para as plantas mas, também, de um conjunto de fatores, dentre eles os relacionados ao solo, é que o Governo do Estado da Paraíba contratou, da Empresa Estadual de Pesquisa Agropecuária da Paraíba (EMEPA) o levantamento pedológico das terras das várzeas do município de Sousa, com o intuito de selecionar áreas a serem irrigadas com as águas do "Canal da Redenção", que liga o açude de Coremas ao município de Sousa, numa extensão de 57km.

Apesar dos solos da região semi-árida apresentarem, normalmente, argila de atividade alta e elevados percentuais de saturação de bases, os elevados valores de $\mathrm{pH}$ e a presença de sais limitam, muitas vezes, o desenvolvimento das plantas. Segundo Malavolta (1980) o pH do solo influencia, de forma indireta, o desenvolvimento das culturas, evidenciado através das mudanças que provoca nas disponibilidades dos elementos essenciais existentes no solo. Quando o pH é ligeiramente alcalino, tendendo a alcalino, o desenvolvimento das culturas pode ser prejudicado devido à baixa disponibilidade do fósforo e/ou dos micronutrientes como ferro, manganês, cobre e zinco podendo, segundo Sharpley et al. (1988) ocorrer aumento do teor de fósforo na solução de solos sódicos, quando a saturação por sódio no complexo de troca aumentar. O sódio, substituindo o cálcio, o magnésio e o alumínio nos sítios de troca, faz com que o potencial negativo da superfície aumente, conduzindo à dessorção de P; no entanto, quando os solos sódicos ou salinosódicos são corrigidos com gesso, devido à formação de fosfatos de cálcio insolúveis, ocorre redução nos teores de $\mathrm{P}$ disponível (Santos, 1995) e, por isto, quando esses solos são corrigidos, deve-se adotar práticas que reduzam a precipitação do $\mathrm{P}$.

Da mesma forma que o $\mathrm{pH}$, a presença de sais nos solos afeta o rendimento de várias culturas, devido à baixa absorção de água pelas raízes, causada pelos efeitos do potencial osmótico (Bernstein, 1975) ou devido à toxidade de íons, quando a salinidade é dada principalmente por cloreto de sódio. Segundo Santos \& Muraoka (1997) o excesso de sódio nos solos, da mesma forma que o estresse osmótico, também pode reduzir a população microbiana, fazendo com que a taxa de mineralização seja baixa diminuindo, assim, a liberação de enxofre e nitrogênio da matéria orgânica para as plantas.

Com base no exposto, o presente trabalho teve, como objetivo, avaliar, de forma exploratória, a fertilidade dos solos das várzeas de Sousa, no Estado da Paraíba, fornecendo subsídios ao manejo adequado dos mesmos.

\section{MATERIAL E MÉTODOS}

A área objeto do trabalho abrange uma superfície de 13.568ha e localiza-se na confluência do rio do Peixe com o Piranhas, nas proximidades da cidade de Sousa, no Estado da Paraíba, mesorregião do Sertão Paraibano, especificamente na microrregião de Sousa. Localizada geograficamente entre os paralelos $6^{0} 19^{\prime}$ e $7^{0} 24^{\prime}$ 'S de latitude e os meridianos $37^{\circ} 55^{\prime} \mathrm{e}$ $38^{\circ} 46^{\prime}$ W.Gr. de longitude, com altitude média de $225 \mathrm{~m}$ limita-se, ao Norte, com o Rio do Peixe, ao Sul com o Rio Piranhas, a Leste com os municípios de Aparecida e São Domingos e a Oeste com o município de Sousa e o Perímetro
Irrigado de São Gonçalo; o clima se caracteriza por ser quente e pela temperatura média anual, geralmente superior a $24^{\circ} \mathrm{C}$, com amplitude térmica inferior a $4^{\circ} \mathrm{C}$. Segundo os dados de precipitação pluviométrica registrados na Estação Climatológica do Perímetro Irrigado de São Gonçalo, PB, a média dos totais anuais de uma série temporal de dezesseis anos situa-se em torno de $899,1 \mathrm{~mm}$, dos quais aproximadamente $60,9 \%$ caem no trimestre fevereiro-abril.

As formas de relevo encontradas na região vão de plano, suave ondulado a ondulado, enquanto a vegetação natural predominante é a caatinga hiperxerófila, caracterizada por vegetais de porte variável arbóreo ou arbustivo e de caráter xerófilo, com grande quantidade de plantas espinhosas, cactáceas e bromeliáceas.

As classes de solo da área em estudo, em níveis representativos, são Vertissolos e solos Aluviais eutróficos, os quais ocorrem em $26,60 \%$ e $39,20 \%$ da área, respectivamente, seguindo-se, em menor grau de importância, os Podzólicos Vermelho-Amarelo eutróficos, que acontecem em 22,80\% da área (Figura 1). No estudo pedológico da referida área, foram abertos e descritos sessenta e seis perfis, os quais foram locados obedecendo a uma malha quadrática, determinada previamente para cada classe de solo, através de fotointerpretação. Para o presente trabalho consideraram-se apenas as amostras dos horizontes superficiais e dos primeiros

\section{Estado da Paraíba}

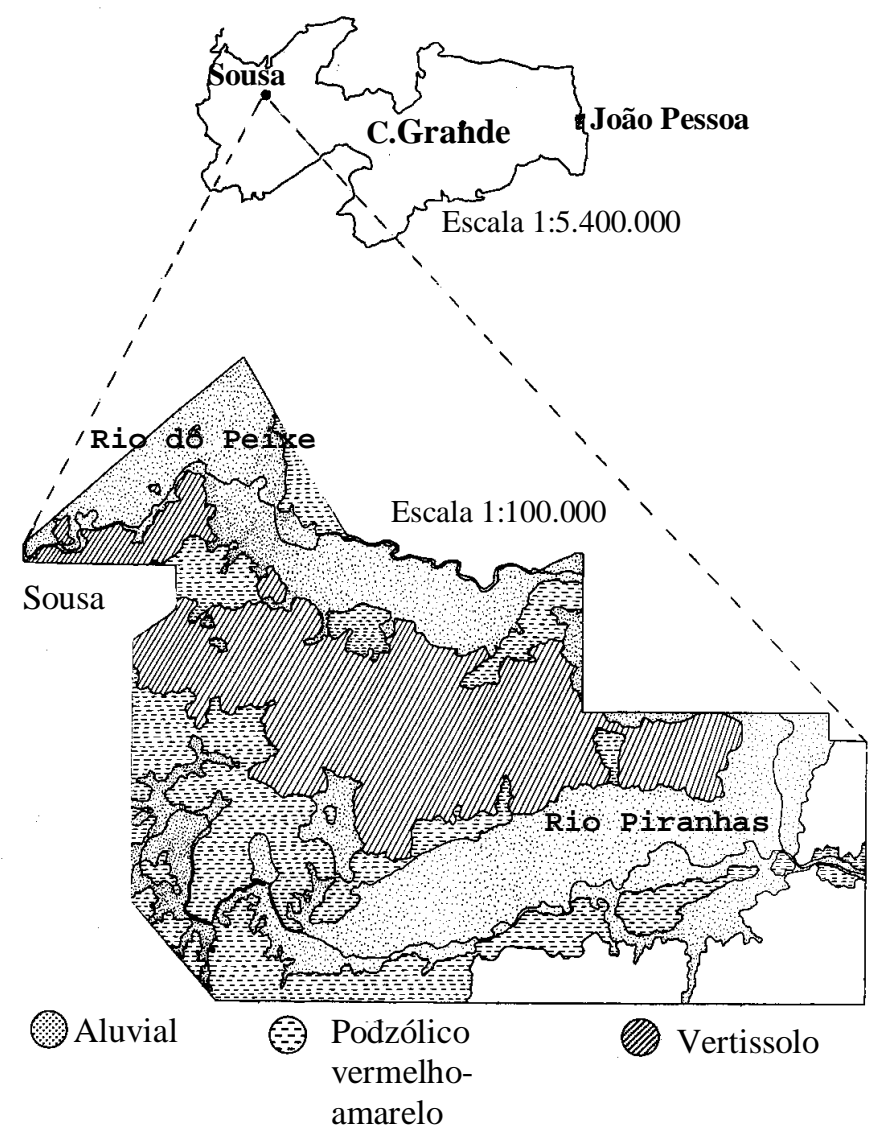

Figura 1. Mapa dos solos das várzeas de Sousa e sua localização no Estado da Paraíba (SEMARH/EMEPA, 1998) 
subsuperficiais de cada perfil. As profundidades dos horizontes superficiais do Vertissolo, do solo Aluvial eutrófico e do Podzólico Vermelho-Amarelo, variaram de $0-10 \mathrm{~cm}$ a $0-40 \mathrm{~cm}$, de $0-10 \mathrm{~cm}$ a $0-70 \mathrm{~cm}$ e de $0-4 \mathrm{~cm}$ a $0-48 \mathrm{~cm}$, respectivamente; nesta mesma ordem, a profundidade dos horizontes subsuperficiais variaram de $10-45 \mathrm{~cm}$ a $35-123 \mathrm{~cm}$, de $11-40$ a $25-110 \mathrm{~cm}$ e de $9-33 \mathrm{~cm}$ a $10-112 \mathrm{~cm}$.

As análises químicas das amostras de terra foram realizadas no Laboratório de Irrigação e Salinidade do Departamento de Engenharia Agrícola, o qual faz parte do Centro de Ciências e Tecnologia da Universidade Federal da Paraíba, e consistiram em: $\mathrm{pH}(1: 2,5)$ em água; cálcio mais magnésio $\left(\mathrm{Ca}^{++}+\mathrm{Mg}^{++}\right)$, potássio $\left(\mathrm{K}^{+}\right)$, sódio $\left(\mathrm{Na}^{+}\right)$, alumínio $\left(\mathrm{Al}^{+++}\right)$, hidrogênio $\left(\mathrm{H}^{+}\right)$, fósforo (P) e matéria orgânica (MO) de acordo com EMBRAPA (1997) e condutividade elétrica (CE) no extrato de saturação obtido da pasta saturada, de acordo com Richards (1954). Em função dessas determinações foram calculadas a soma de bases (S), a capacidade de troca catiônica (CTC), a percentagem de saturação por base $(\mathrm{V})$ e a percentagem de sódio trocável (PST).

Os níveis adotados na interpretação dos resultados dos parâmetros químicos determinados com suas respectivas unidades, adaptadas ao Sistema Internacional de Unidades (Cantarella \& de Andrade, 1992) são apresentados na Tabela 1.

Após a interpretação dos parâmetros químicos, determinados por amostra de terra, calculou-se a percentagem de amostras dentro de cada nível de interpretação, sendo alguns valores apresentados em tabela e outros plotados em histogramas.

\section{RESULTADOS E DISCUSSÃO}

$\mathrm{Na}$ Figura 2 são apresentados os histogramas correspondentes à distribuição percentual das amostras de terra dos horizontes superficial e subsuperficial dos solos estudados, em diferentes classes dos parâmetros químicos analisados: $\mathrm{pH}$, $\mathrm{Ca}^{++}+\mathrm{Mg}^{++}, \mathrm{K}^{+}, \mathrm{P}$ e MO. Observa-se que 53,33\% das amostras de terra dos horizontes superficiais do Vertissolo apresentam $\mathrm{pH}$ moderadamente alcalino, 26,67\% alcalino e o restante, 20\%, $\mathrm{pH}$ praticamente neutro. Esses níveis de $\mathrm{pH}$ são decorrentes, principalmente, dos altos teores das bases trocáveis encontradas no solo e da ausência dos íons alumínio e hidrogênio (Tabela 2) uma vez que a baixa precipitação pluviométrica da região contribuiu para que a lixiviação das referidas bases fosse pequena. Em relação às amostras de terra dos horizontes subsuperficiais, $86,67 \%$ possuem valores de $\mathrm{pH}$ classificados como alcalinos e apenas $13,33 \%$ possuem $\mathrm{pH}$ praticamente neutro.

O solo Aluvial eutrófico apresenta reação desde moderadamente ácida até alcalina, apesar de $58,06 \%$ das amostras de terra dos horizontes superficiais analisadas apresentarem $\mathrm{pH}$ praticamente neutro; entretanto, há uma tendência à alcalinidade nos horizontes subsuperficiais, o que pode ser constatado pelas percentagens de amostras com $\mathrm{pH}$ classificado como moderadamente alcalino $(8,3)$ e alcalino $(>8,4)$ as quais aumentaram de 19,35 e $9,68 \%$ (amostras de terra dos horizontes superficiais) para 22,58 e 48,39\% (amostras de terra dos horizontes subsuperficiais) respectivamente.

A figura referente ao $\mathrm{pH}$ das amostras do solo Podzólico Vermelho-Amarelo, indica que a maioria das amostras de terra dos horizontes superficiais, $75 \%$, devido à presença de $\mathrm{H}^{+} \mathrm{e}$

Tabela 1. Classificação de parâmetros químicos, de acordo com seus respectivos níveis

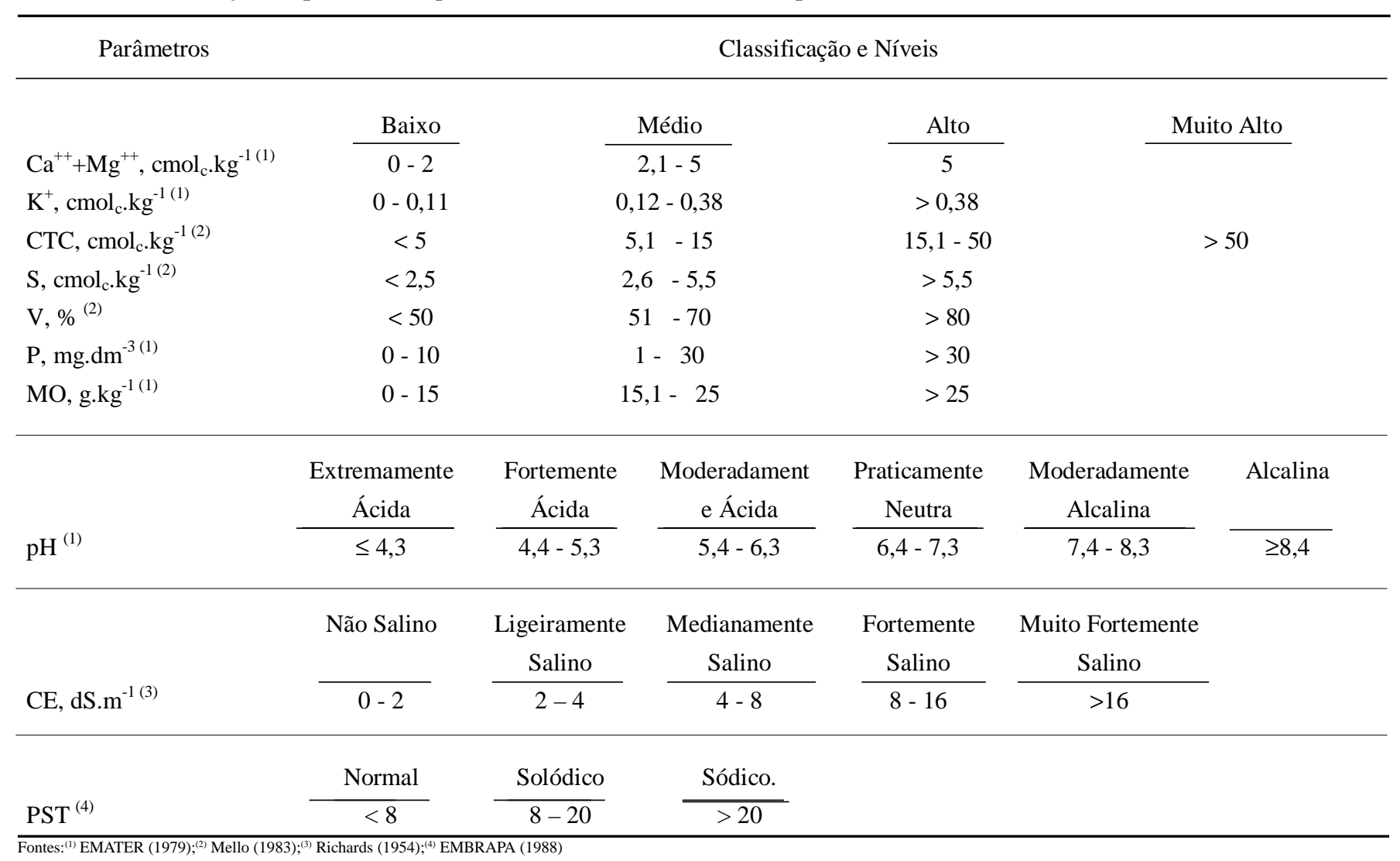


A. Vertissolo
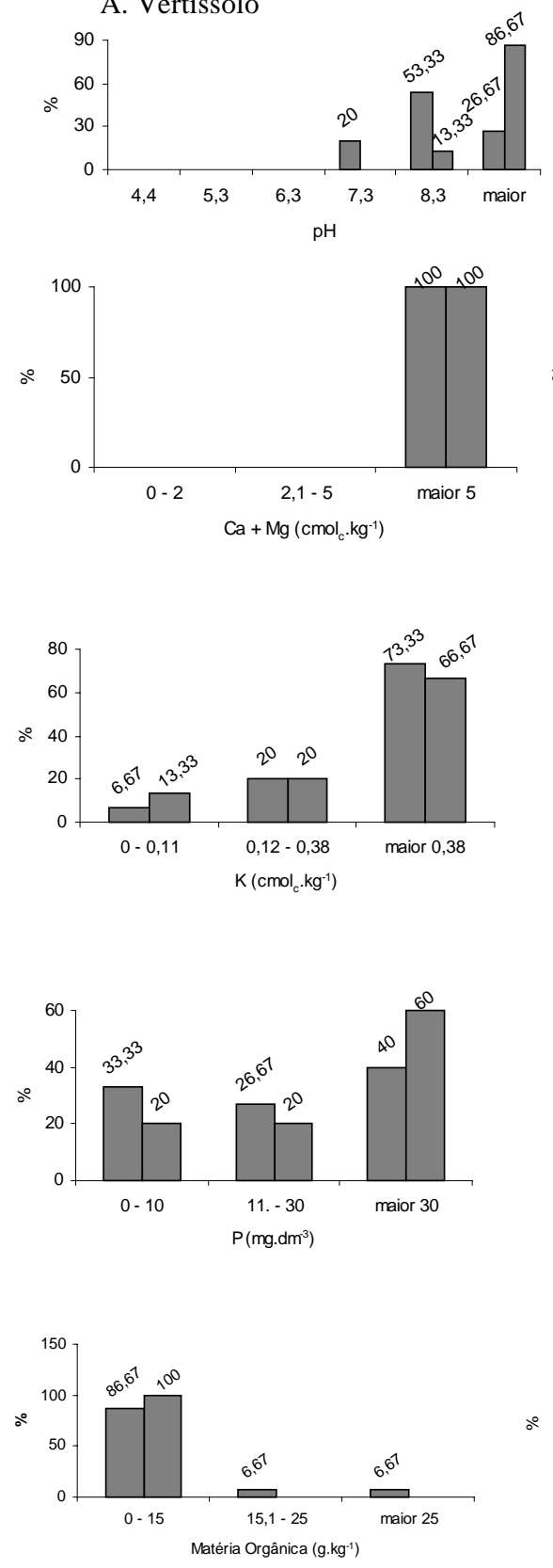

B. Aluvial eutrófico
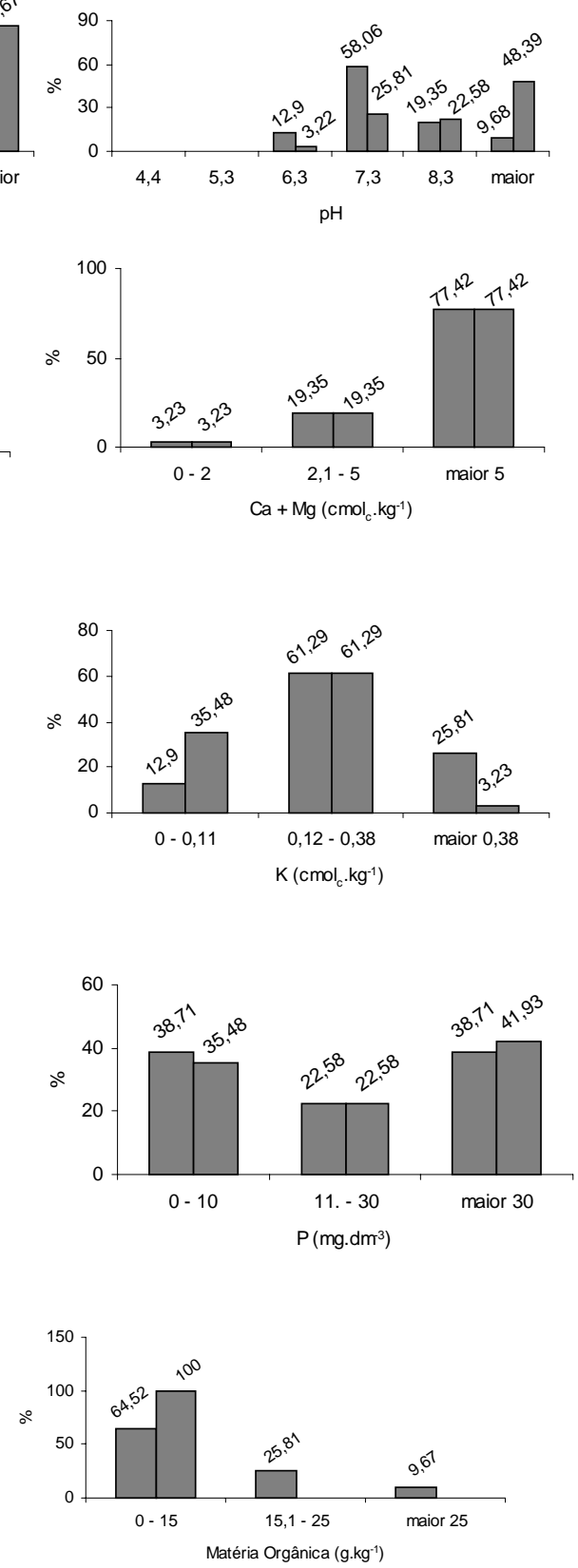

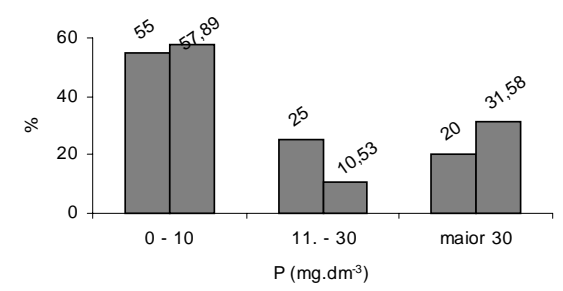

C. Podzólico Vermelho-Amarelo
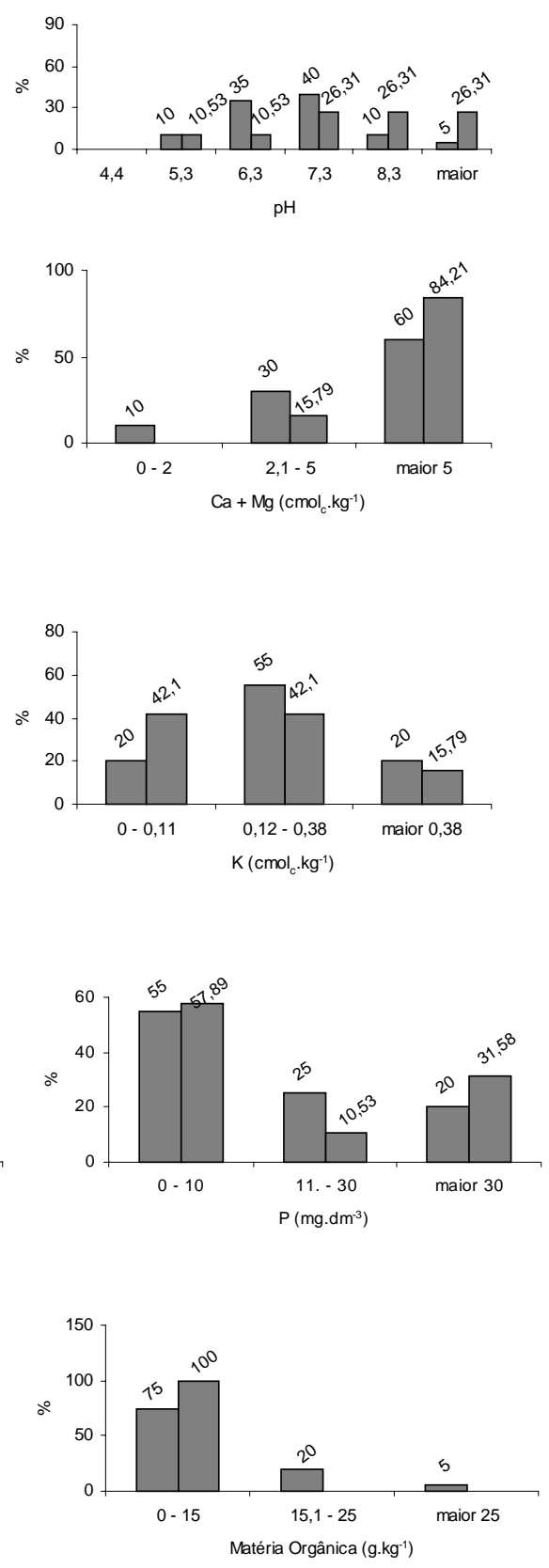

Horizonte Superficial

Horizonte Subsuperficial

Figura 2. Distribuição percentual das amostras de terra dos horizontes superficiais e subsuperficiais dos solos vertissolo (A), aluvial eutrófico (B) e podzólico vermelho-amarelo (C), em diferentes classes das características químicas, reação do solo $(\mathrm{pH})$, cálcio mais magnésio $\left(\mathrm{Ca}^{++}+\mathrm{Mg}^{++}\right)$, potássio $(\mathrm{K})$, fósforo $(\mathrm{P})$ e matéria orgânica .

$\mathrm{Al}^{+++}$(Tabela 2) apresenta reação moderadamente ácida e praticamente neutra, enquanto $78,93 \%$ das amostras de terra dos horizontes subsuperficiais apresentam reação variando de neutra a alcalina, provavelmente devido ao aumento das bases trocáveis no solo e da percentagem de saturação em bases (Tabela 2).

Em geral, observa-se que houve aumento de $\mathrm{pH}$ com a profundidade, em razão não apenas do aumento da percentagem de saturação por bases mas, também, do aumento da salinidade (Tabela 2) e, provavelmente, à presença de altas concentrações de íons carbonato e bicarbonato de sódio não apresentadas neste trabalho. Essa mesma tendência dos valores de $\mathrm{pH}$ foi observado por Souza et. al. (1993) e Lyra et al. (1995) em vários perfis de Vertissolo da região do baixo-médio São Francisco, Estado da Bahia.

Segundo Malavolta (1980) quando o pH é ligeiramente alcalino, tendendo a alcalino, como é o caso, em geral, dos solos estudados, o desenvolvimento das culturas pode ser prejudicado devido à baixa disponibilidade do fósforo porém, analisando-se os histogramas referentes à fósforo (Figura 2) verifica-se que os teores do elemento nos três solos variam de baixo até alto. Esta variação também foi observada por Lyra et al. (1995) em Vertissolos. A presença de alto teor de fósforo na solução dos 
Tabela 2. Distribuição percentual das amostras de terra dos horizontes superficiais e subsuperficial do Vertissolo, solo Aluvial eutrófico e Podzólico Vermelho-Amarelo, em diferentes classes das características químicas, capacidade de troca catiônica (CTC), soma de bases trocáveis (S), percentagem de saturação em bases (V), salinidade (CE, no extrato de saturação) e percentagem de sódio trocável (PST)

\begin{tabular}{|c|c|c|c|c|c|c|}
\hline \multirow{3}{*}{ Classificação } & \multicolumn{2}{|c|}{ Vertissolo } & \multicolumn{2}{|c|}{ Aluvial } & \multicolumn{2}{|c|}{ Podzólico Vermelho-Amarelo } \\
\hline & \multicolumn{2}{|c|}{ Horizonte } & \multicolumn{2}{|c|}{ Horizonte } & \multicolumn{2}{|c|}{ Horizonte } \\
\hline & Superficial & Subsuperficial & Superficial & Subsuperficial & Superficial & Subsuperficial \\
\hline & \multicolumn{6}{|c|}{ Capacidade de Troca Catiônica (CTC) } \\
\hline Baixa & & & & & 10 & \\
\hline Alta & 86,67 & 93,33 & 45,16 & 61,29 & 45 & 47,37 \\
\hline Muito Alta & 13,33 & 6,67 & & & & \\
\hline
\end{tabular}

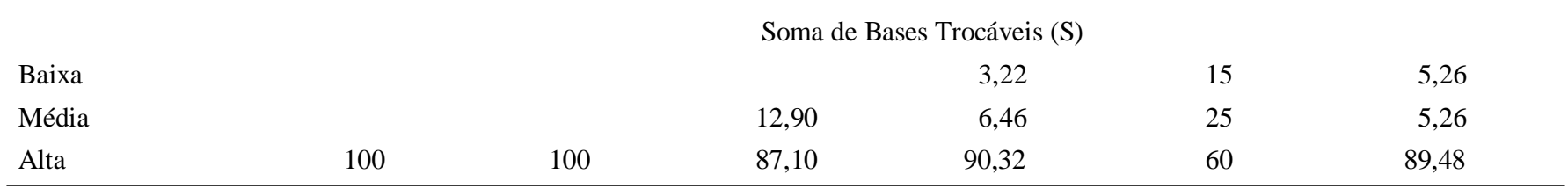

Percentagem de Saturação em Bases (V)

\begin{tabular}{|c|c|c|c|c|c|c|}
\hline Baixa & & & & 3,22 & 35 & 10,53 \\
\hline Média & & & 16,13 & - & 5 & 5,26 \\
\hline Boa & & & 6,45 & 3,22 & 15 & 5,26 \\
\hline Alta & 100 & 100 & 77,42 & 93,56 & 45 & 78,95 \\
\hline
\end{tabular}

\begin{tabular}{|c|c|c|c|c|c|c|}
\hline \multirow[b]{2}{*}{ Não salino } & \multicolumn{6}{|c|}{ Salinidade (CE no extrato de saturação) } \\
\hline & 100 & 93,33 & 90,32 & 67,75 & 95 & 89,48 \\
\hline Ligeiramente salino & & & 6,46 & 19,35 & 5 & 5,26 \\
\hline Medianamente salino & & 6,67 & & 12,90 & & 5,26 \\
\hline Fortemente salino & & & 3,22 & & & \\
\hline
\end{tabular}

\begin{tabular}{lrccrrr} 
& \multicolumn{5}{c}{ Percentagem de Sódio Trocável (PST) } \\
Normal & 86,67 & 53,33 & 67,74 & 35,48 & 90,00 & 63,16 \\
Solódico & 13,33 & 40,00 & 16,13 & 22,58 & 5,00 & 5,26 \\
Sódico & & 6,67 & 16,13 & 41,93 & 5,00 & 31,58 \\
\hline
\end{tabular}

solos sódicos está relacionada, provavelmente, ao aumento da PST (Tabela 2) o qual, segundo Sharpley et al. (1988) pode provocar a dessorção de $\mathrm{P}$.

Conforme o que se apresenta na Tabela 2, alguns locais da área estudada já apresentam problemas de salinidade, principalmente nos horizontes subsuperficiais, e de sodicidade, ou seja, PST acima de 20. A presença de sódio nas amostras de terra dos horizontes superficiais do Vertissolo não é prejudicial, uma vez que a percentagem de saturação do elemento no complexo sortivo, encontra-se abaixo de 20 em $100 \%$ das amostras de solo analisadas; entretanto, nos horizontes subsuperficiais do Vertissolo ocorre aumento no teor de sódio, o que pode ser constatado pelo aumento na percentagem de amostras de terra com PST variando de 8 a 20 e pela ocorrência de $6,67 \%$ de amostras de terra com problema de sodicidade (PST > 20). Em relação ao solo Aluvial eutrófico, pode-se dizer que a presença de sódio no complexo sortivo de $67,74 \%$ das amostras de terra dos horizontes superficiais, não acarreta problemas, porém se observa tendência à sodicidade, uma vez que 22,58 e $41,93 \%$ das amostras de terra dos horizontes subsuperficiais apresentam PST entre 8 e 20 e acima de 20, respectivamente; esta mesma tendência pode ser observada nas amostras de terra do solo Podzólico Vermelho-Amarelo (Tabela 2). Com base nos dados de todas as amostras de terra dos horizontes superficiais, pode-se dizer que aproximadamente, em 18,46\% da área estudada, ou seja, em torno de 2.500ha, a PST está acima de 8 (solos solódicos e sódicos); considerando-se as amostras de terra dos horizontes subsuperficias, esta percentagem sobe para $46,09 \%$, que corresponde a mais ou menos 6.260 ha. $\mathrm{O}$ fato de aumentar a sodicidade nos horizontes subsuperficiais é preocupante, uma vez que, tendo os horizontes superficiais profundidade média em torno de $0,40 \mathrm{~m}$, as raízes das plantas atingem, com facilidade, aqueles horizontes, sendo prejudicadas pela presença do elemento sódio, tanto no que diz respeito a toxidade às plantas e ao desbalanço nutricional que pode causar quando a relação $\mathrm{Na}: \mathrm{Ca}$ se torna alta, como por reduzir a mineralização, o que diminui a liberação de enxofre e nitrogênio da matéria orgânica para as plantas (Santos \& Muraoka, 1977). 
Considerando-se que os solos estudados serão provavelmente submetidos à irrigação, o problema da sodicidade torna-se ainda mais preocupante, uma vez que o excesso de sódio trocável nos solos altera os parâmetros físico-hídricos. A condutividade hidráulica pode ser reduzida devido à dispersão das argilas que por sua vez provoca redução na taxa de infiltração, redistribuição e evaporação da água no solo, que pode resultar em uma temporária inundação da superfície do solo, que prejudica a germinação das sementes, devido à falta de oxigênio; esta condição também resulta em um período mais prolongado de umedecimento, dificultando as operações de manejo (Santos \& Muraoka, 1997); portanto, estes solos deverão ser manejados adequadamente no sentido de serem reduzidos a concentração do sódio tracável, a condutividade elétrica e o pH.

Com base no que é apresentado na Figura 2 em relação ao $\mathrm{K}^{+} \mathrm{e} \mathrm{Ca}^{++}+\mathrm{Mg}^{++}$pode-se dizer que, em geral, na maior parte da área estudada o desenvolvimento de culturas não é prejudicado pela deficiência desses elementos, uma vez que seus teores variam de médio a alto. Esta variação influencia os valores de CTC, os quais são de grande importância no que diz respeito à fertilidade de um solo, uma vez que indicam a capacidade deste para adsorver cátions em forma trocável, os quais, em geral, irão servir de nutrientes às plantas.

Conforme mostra a Tabela 2, a CTC do Vertissolo varia entre alta e muito alta, a do solo Aluvial eutrófico entre moderada a alta e a do solo Podzólico Vermelho-Amarelo entre baixa e alta, nas amostras de terra dos horizontes superficiais, e moderada a alta nas amostras de terra dos horizontes subsuperficiais. A CTC desses solos é, praticamente, função do tipo e da quantidade de argila que apresentam, uma vez que em quase toda a área de estudo o teor de matéria orgânica é considerado baixo (Tabela 2).

Ante o exposto, e quanto aos nutrientes essenciais ao desenvolvimento das plantas $\left(\mathrm{P}, \mathrm{K}^{+}, \mathrm{Ca}^{++}+\mathrm{Mg}^{++}\right)$poder-se-ia dizer que os três solos predominantes na área em estudo, Vertissolo, Aluvial eutrófico e Podzólico Vermelho-Amarelo; estão bem supridos; entretanto, um solo só é considerado fértil quando, além de conter quantidades suficientes dos nutrientes essenciais às plantas, está livre de materiais tóxicos e apresenta propriedades físicas satisfatórias (Mello et al., 1983). Desta forma, as fortes limitações que esses solos apresentam, tanto no aspecto da química de solo, comentado anteriormente, como no da física devido a presença de argilas de alta atividade, manto pedregoso e solos rasos (SEMARH/EMEPA, 1998), os impedem, a princípio, de serem classificados como tal; o Vertissolo, por exemplo, apresenta alto teor de argila expansiva, plasticidade e pegajosidade altas e baixa permeabilidade (SEMARH/EMEPA, 1998) o que dificultará a sua drenagem favorecendo, assim, tanto o escoamento superficial das águas $\mathrm{e}$, consequentemente, a erosão do solo, como a evaporação da água acumulada no perfil e, em consequiência, a salinização; essas características também dificultam a mecanização da área. Em relação ao solo Aluvial eutrófico, deduz-se que nas áreas que apresentam sodicidade, provocando dispersão de argila, ocorrem os mesmos problemas provocados pela má drenagem. Estas observações são extensivas às áreas do Podzólico Vermelho-Amarelo, que apresentaram PST acima de $20 \%$.

\section{CONCLUSÃO}

Com base na avaliação exploratória deste trabalho, pode-se concluir que, apesar dos solos estudados apresentarem níveis satisfatórios de potássio e cálcio mais magnésio, para que sejam considerados realmente férteis é necessário que, antes de qualquer tipo de atividade agrícola, seus problemas sejam corrigidos, tanto no que diz respeito à redução da salinidade e/ ou sodicidade, como ao fornecimento de fósforo e matéria orgânica e, durante o processo produtivo, sejam manejados adequadamente.

\section{REFERÊNCIAS BIBLIOGRÁFICAS}

BERNSTEIN, L. Effects of salinity and sodicity on plant growth. Annual Review of Plant Phytopathology, Stanford, 13:295-312, 1975.

CANTARELLA, H. \& ANDRADE, J.C. de. O Sistema Internacional de Unidades e a Ciência do Solo. Boletim Informativo da Sociedade Brasileira de Ciência do Solo. Campinas, , v.17, n.3, p.91-102

EMATER. Sugestões de adubação para o Estado da Paraíba; $1{ }^{2}$ aproximação. João Pessoa: EMATER-PB, 1979.

EMBRAPA. Centro Nacional de Pesquisa de Solos. Manual de métodos de análise de solo. 2 ed. rev. Rio de Janeiro: Centro Nacional de Pesquisa de Solos, 1997. 212p.

EMBRAPA. Serviço Nacional de Levantamento e Conservação de Solos. Critérios para distinção de classes de solos e de fases de unidades de mapeamento; normas em uso pelo SNLCS. Rio de Janeiro: EMBRAPA-SNLCS, 1988.

LYRA, M.C.C.P.; RIBEIRO, M.R.; RODRIGUES, J.J.V. Caracterização de vertissolos em projetos de irrigação na região do baixo-médio São Francisco: II. Propriedades morfológicas, físicas e químicas. Revista Brasileira de Ciêcia do Solo, Campinas, v.19, p.441-448, 1995.

MALAVOLTA, E. Elementos de nutrição mineral de plantas. São Paulo: Agronômica Ceres, 1980. 251p.

MELLO, F.A.F.; BRASIL SOBRINHO, M.O.C.; ARZOLLA, S.; SILVEIRA, R.I.; COBRA NETTO, A.; KIEHL, J.C. Fertilidade do solo. São Paulo: Nobel, 1983.400p.

RICHARDS, L.A. (ed). Diagnosis and improvement of saline and alkali soils. Washington D.C.: United States Salinity Laboratory Staff, 1954. 160p. (USDA. Agriculture Handbook,60).

SANTOS, R.V. dos. Correção de um solo salino-sódico e absorção de nutrientes pelo feijoeiro vigna (Vigna unguiculata (L.) WALP). Piracicaba: ESALQ. 1995. 120p. Tese Doutorado

SANTOS, R.V.; MURAOKA, T. Interações salinidade e fertilidade do solo. In: GHEYI, H.R.; QUEIROZ, J.E.; MEDEIROS, J.F. Manejo e controle da salinidade na agricultura irrigada. Campina Grande: UFPB/SBEA, 1997. cap. 9, p.289-317.

SEMARH/EMEPA. Estudos básicos de aproveitamento hidroagrícola das várzeas de Sousa: Avaliação detalhada de solos. v.1. João Pessoa, PB: EMEPA-PB, 1998. 271p.

SHARPLEY, A. N.; CURTIN, D.; SYERS, J.K. Changes in water-extractability of soil inorganic phosphate induced by sodium satureted benchmark soil. Soil Science Society Australian Journal p.637-40, 1988

SOUZA, E.A. de; RIBEIRO, M.R.; FERREIRA, M. da G. de V. X. Caracterização e gênese de solos do baixo de Irecê, BA. Revista Brasileira de Ciêcia do Solo, Campinas, v.17, p.89-97, 1993. 